\title{
Çok Düşük Doğum Ağırlıklı Bebeklerde Tam Enteral Beslenmeye Geçiş Süresine Etki Eden Faktörler
}

\section{Factors Affecting the Full Enteral Feeding in Very Low Birth Weight Preterm Infants}

\author{
Merve KÜÇÜKOĞLU KESER¹, Aslihan KÖSE ÇETINKAYA², Esin OKMAN¹, Esra BEŞER ÖZMEN1, \\ Fatma Nur SARI ${ }^{1}$, Cüneyt TAYMAN¹, Evrim ALYAMAÇ DIZDAR ${ }^{1}$
}

${ }^{1}$ Sağlık Bilimleri Üniversitesi, Ankara Şehir Hastanesi, Yenidoğan Kliniği, Ankara, Türkiye

${ }^{2}$ Sağlık Bilimleri Üniversitesi, Ankara Eğitim ve Araştırma Hastanesi, Yenidoğan Kliniği, Ankara, Türkiye

\section{Öz}

Amaç: Tam enteral beslenmeye erken geçiş protein katabolizmasını önleyerek bebeklerin büyüme ve gelişimine olumlu katkı sağlar. Bu çalışmada çok düşük doğum ağılıklı preterm bebeklerde tam enteral beslenmeye geçiş süresine etki eden faktörlerin belirlenmesi amaçlandı.

Gereç ve Yöntemler: Doğum ağılığı $\leq 1500$ gr ve gestasyon yaşı $\leq 32$ hafta olan preterm bebeklerin demografik verileri, tam enteral beslenmeye geçiş süreleri, hastanede yatış süreleri, taburculuktaki vücut ağırlıkları ve baş çevreleri, günlük kilo alımları, bronkopulmoner displazi (BPD), nekrotizan enterokolit (NEK), intraventriküler kanama (IVK), respiratuar distres sendromu (RDS), geç neonatal sepsis (GNS) ve mortalite oranları kaydedildi. Veriler tam enteral beslenmeye geçiş zamanına göre ilk 10 günde geçenler erken, 10 günden uzun sürede geçenler ise geç şeklinde gruplandırlarak karşılaştırıldı.

Bulgular: Çalışmaya 474 bebek dahil edildi. Bebeklerin 91'i, ilk 10 günde, 383'ü ise 10 günden sonra tam enteral beslenmeye geçen bebeklerdi. Ortanca (IQR) gestasyon haftası sırasıyla 29 (28-30) ve 28 (27-29) hafta, doğum ağırlığı 1240 (1080-1350) gr ve 1030 (850-1190) gr'dı. Tam enteral beslenmeye erken geçen bebeklerde hastanede yatış süresi daha kısa olarak saptandı $(p<0.01)$. GNS ve BPD oranları enteral beslenmeye geç ulaşanlarda anlamlı olarak daha yüksekti (p<0.01). NEK, Grade 3-4 IVK ve mortalite oranları gruplar arasında benzerdi. Doğum ağırlığının düşük olması, RDS varlığı ve annede preeklampsi varlığı, tam enteral beslenmeye geçiş zamanının gecikmesi açısından risk faktörleri olarak bulundu.

Sonuç: Yenidoğan yoğun bakım ünitelerinde izlenen preterm bebeklerin tam enteral beslenmeye erken başlaması morbiditeler üzerine fayda sağlar. Bu durum bebeklerde hastane yatış sürelerini azaltarak büyümelerine katkı sağlayabilir. Preterm doğumların önlenmesi, RDS ve preeklampsinin engellenmesi, tam enteral beslenmeye geçişi kolaylaştırmaktadır.

Anahtar Sözcükler: Beslenme, Çok düşük doğum ağıllığı, Enteral beslenme, Preterm

\section{ABSTRACT}

Objective: Early transition to full enteral nutrition prevents protein catabolism and has a positive impact on the growth and development of infants. The aim of this study was to determine the factors affecting the time to full enteral feeding in very low birth weight infants.

\section{(1)}

KÜÇÜKOĞLU KESER M KÖSE ÇETINKAYA A OKMAN E BEȘER ÖZMEN E

SARI FN

TAYMAN C ALYAMAC DIZDARE
0000-0001-5350-6329 0000-0003-0265-0229 :0000-0002-0846-4032 :0000-0002-3368-1514 :0000-0003-4643-7622 : 0000-0002-1861-2262 0000-0001-8956-0917
Çıkar Çatışması / Conflict of Interest: Tüm yazarlar adına, sorumlu yazar çıkar çatışması olmadığını belirtir.

Etik Kurul Onayı / Ethics Committee Approval: Bu çalısmada ulusal ve uluslararası etik kurallara uyulmuştur. Çalışma için Dr. Zekai Tahir Burak Kadın Sağlığı ve Hastalıkları EAH, Klinik Araştırmalar Etik Kulu’ndan 06.03.2018 tarihli ve 19/2018 karar numarası ile onay alınmıştır. Kayıt sırasında veliler tarafından araștırmaya katılım için bilgilendirilmiș bir onay imzalanmıștır.

Yazarların katkısı / Contribution of the Authors: KÜçÜKOĞLU KESER M: Araştırma ve/veya makalenin hipotezini veya fikrini oluşturan, Araştırma/ çalışmanın sorumluluğunu üstlenmek, ilerlemenin seyrini denetlemek, Çalışmanın bütününün veya önemli bölümlerinin yazımında sorumluluk almak, KÖSE ÇETINKAYA A: Araştırma ve/veya makalenin hipotezini veya fikrini oluşturan, Araştırma/çalışmanın sorumluluğunu üstlenmek, ilerlemenin seyrin denetlemek, OKMAN E: Araștırma/çalıșmanın sorumluluğunu üstlenmek, ilerlemenin seyrini denetlemek, BEŞER ÖZMEN E: Araștırma/çalıșmanın sorumluluğunu üstlenmek, ilerlemenin seyrini denetlemek, Çalıșmanın bütününün veya önemli bölümlerinin yazımında sorumluluk almak $\mathbf{S A R I} \boldsymbol{F N}$ : Sonuçarın mantıksal olarak Yorumlanması ve sonuçlandırıması, Çalısmanın bütününün veya önemli bölümlerinin yazımında sorumluluk almak TAYMAN C : Sonuçların mantıksal olarak Yorumlanması ve sonuçlandııııması, ALYAMAC DiZDAR E : Araștırma ve/veya makalenin hipotezini veya fikrini olușturan, Sonuçların mantıksal olarak Yorumlanması ve sonuçlandırıması, Çalışmanın bütününün veya önemli bölümlerinin yazımında sorumluluk almak

Atıf yazım şekli / How to cite : Küçükoğlu Keser M, Köse Çetinkaya A, Okman E, Beşer Özmen E, Sarı FN, Tayman C ve ark. Çok Düşük Doğum Ağırlıklı Bebeklerde Tam Enteral Beslenmeye Geçiș Süresine Etki Eden Faktörler. Türkiye Çocuk Hast Derg 2021;15:257-261.
Yazışma Adresi / Correspondence Address:

Merve KÜçÜKOĞLU KESER

Ankara Șehir Hastanesi, Yenidoğan Kliniği, Ankara, Türkiye

E-posta: m_koglu@hotmail.com
Geliş tarihi / Received : 03.02.2020 Kabul tarihi / Accepted : 03.06.2020 Elektronik yayın tarihi $\quad: 28.09 .2020$ Online published

DOI: $10.12956 /$ tchd.688924 
Material and Methods: Demographic data of infants with birth weight $\leq 1500 \mathrm{~g}$ and gestational age $\leq 32$ weeks, time to full enteral feeding, weights and head circumference at discharge, daily weight gain, duration of hospital stay, bronchopulmonary dysplasia (BPD), necrotizing enterocolitis (NEC), intraventricular hemorrhage (IVH), respiratory distress syndrome (RDS), late neonatal sepsis (LNS) and mortality rates were recorded. Data were compared by grouping according to the time of transition to full enteral nutrition as early in the first 10 days and delayed in more than 10 days.

Results: Totally 474 infants were included in the study. Of those 91 infants achieved full enteral feeding in the first 10 days and 383 of them after 10 days. Median gestational age were 29 and 28 weeks and birth weights were $1240 \mathrm{~g}$ and $1030 \mathrm{~g}$ respectively. While the duration of hospital stay was shorter in the early enteral feeding group $(p<0.01$ ), late neonatal sepsis and BPD rates were significantly higher in late arriving enteral feeding ( $p<0.01)$. NEC, Grade 3-4 IVH and mortality rates were similar between the groups. Low birth weight, presence of RDS and maternal preeclampsia were found to be risk factors for delayed transition to full enteral feeding.

Conclusion: Early achievement of full enteral feeding in very low birth weight preterm infants might have beneficial effects on morbidities. This might contribute to the growth of infants by decreasing duration of hospitalization. Prevention of preterm births, prevention of RDS and preeclampsia facilitate the transition to full enteral nutrition.

Key Words: Nutrition, Very low birth weight infants, Enteral feeding, Preterm

\section{GiRiş}

Çok düşük doğum ağırlıklı bebeklerde tıbbi sorunlar nedeni ile beslenmeye istenilen zamanda başlanamayabilir (1). İlk günlerde yeterli enteral beslenemeyen bebeğe, büyüme geriliğini önlemek için total parenteral beslenme başlanmalıdır. Enteral beslenmeyi tolere eden bebeğin de mümkün olan en kısa sürede tam enteral beslenmeye geçişi sağlanmalıdır (2).

Erken enteral beslenme ve yoğun erken parenteral beslenme büyüme geriliğini azaltmakta, bebeğin mental gelişimsel skorlarını iyileştirmektedir $(3,4)$.

Çok düşük doğum ağırlıklı, özellikle de aşırı düşük doğum ağırlıklı preterm bebeklerde beslenme intoleransının sık görülmesi ve bu bebeklerde ciddi bir mortalite ve morbidite nedeni olan NEK riski istenilen beslenme hedeflerine ulaşılmasını engellemektedir (57). Bu nedenle enteral beslenmenin optimum başlangıç zamanı ve artış hızları bu bebekler için halen belirsizdir (8). Premature beslenmesindeki temel amaç kısa ve uzun vadede oluşabilecek problemleri en aza indirecek şekilde olmalıdır (9).

Bu bebeklerde farklı nedenlerle tam enteral beslenmeye geçiş zamanı gecikebilir. Çalışmamızda çok düşük doğum ağılıklı preterm bebeklerde tam enteral beslenmeye geçiş süresini etkileyen faktörleri araştırmayı amaçladık.

\section{GEREÇ ve YÖNTEMLER}

Bu çalışmada, 2014-2016 tarihleri arasında 3.düzey yenidoğan yoğun bakım ünitesinde izlenen, gebelik haftası $\leq 32$ hafta, doğum ağırlığı $\leq 1500$ gr olan bebekler retrospektif olarak incelendi. Major konjenital ya da kromozomal anomalisi olan, ilk 48 saatte enteral beslenme başlanmayan, hemodinamik instabilitesi olan, ikizden ikize transfüzyon sendromu öyküsü olan ve hayatının ilk 5 günü içinde ölen bebekler çalışma dışında bırakıldı. Çalışma için 06.03.2018 ylında Klinik Araştırmalar Etik Kurulu'ndan onay alındı (Karar no:19/2018).
Tam enteral beslenmeye ilk 10 günde geçen bebekler erken, 10 günden sonra geçen bebekler ise geç olarak gruplandırıld. Türk Neonataloji Derneği'nin önerileri doğrultusunda stabil prematürede ilk günden itibaren tercihen anne sütü ile 10-20 $\mathrm{ml} / \mathrm{kg} / \mathrm{gün}$ beslenme bașlandı. Beslenme miktarı 20-35 ml/kg/ gün şeklinde artırıld. Stabil olmayan yüksek riskli bebekte ise ilk 3-7 gün minimal enteral beslenme, ardından da $20 \mathrm{ml} / \mathrm{kg} /$ gün artış yapıldı. 150 ml/kg/gün'e ulaşan bebelerin tam enteral beslenmeye geçmiş oldukları kabul edildi (2).

Bebeklerin demografik özellikleri, antenatal dönemdeki özellikleri, CRIB skorları, hastanede yatış süreleri, taburculuktaki vücut ağılıkları ve baş çevreleri, günlük kilo alımları, BPD, NEK, IVK, RDS, geç neonatal sepsis ve mortalite oranları kaydedildi. Tam enteral beslenmede gecikmeye neden olan risk faktörleri araştırıldı.

Verilerin istatistiksel analizi SPSS 22.0 paket programında yapıldı. Çalışmaya alınan annelerin demografik özellikleri $n$ (\%) olarak ifade edildi, veriler çarpık dağılıma uyduğundan tanımlayıcı istatistik verilirken ortanca değeri kullanıldı. Karşılaştırmalı analizler için Pearson Ki-Kare testi, ileri analizler için lojistik regresyon analizi kullanıldı. Tüm testlerde istatistiksel anlamılılk değeri $p<0.05$ olarak kabul edildi.

\section{BULGULAR}

Çalışmada toplam 474 hastanın verisi analiz edildi. Doksan bir bebek ilk 10 gün içerisinde, 383 bebek ise 10 günden daha uzun sürede tam enteral beslenmeye geçen bebeklerden oluşmaktaydı. Erken gruptaki bebeklerin tam enteral beslenmeye geçiş süresinin ortancası (IQR), 9 (8-10) gün, geç gruptaki bebeklerin ise 16 (13-22) gündü. Beslenme tipleri yani anne sütü ve/veya formüla ile beslenme açısından iki grup arasında anlamlı fark bulunamadı $(\mathrm{p}=0.286)$.

Hastaların demografik özellikleri Tablo I'de özetlendi. Her iki grup gestasyon haftası, doğum ağırlığı, $\mathrm{C} / \mathrm{S}$ doğum, CRIB skoru ve preeklampsi dışında benzer olarak bulundu. 
Tablo I: Çalışmaya alınan bebeklerin özellikleri

\begin{tabular}{|c|c|c|c|}
\hline & Erken $(n=91)$ & Geç $(n=383)$ & p \\
\hline Cinsiyet (erkek), † & $45(49.5)$ & 185 (48.3) & 0.84 \\
\hline Gestasyon haftası* & $29(28-30)$ & 28 (27-29) & $<0.01$ \\
\hline Doğum ağırığı*, gr & $1240(1080-1350)$ & $1030(850-1190)$ & $<0.01$ \\
\hline C/S doğum, $\dagger$ & $66(72.5)$ & $331(86.4)$ & 0.01 \\
\hline CRIB skoru* & $2(1-3)$ & $3(1-5)$ & $<0.01$ \\
\hline Antenatal steroid, $\dagger$ & 64 (70.3) & 277 (72.3) & 0.81 \\
\hline EMR, $†$ & $22(24.2)$ & $71(18.5)$ & 0.23 \\
\hline Preeklampsi, $†$ & $6(6.6)$ & $77(20.1)$ & 0.02 \\
\hline GHT, $†$ & 3 (3.3) & $27(7)$ & 0.18 \\
\hline Koryoamniyonit, $†$ & $9(9.9)$ & $43(11.2)$ & 0.71 \\
\hline GDM, n (\%) & $5(5.5)$ & $15(3.9)$ & 0.50 \\
\hline Çoğul gebelik, † & $21(23.1)$ & $86(22.5)$ & 0.89 \\
\hline SGA, $†$ & $10(11)$ & 57 (14.9) & 0.33 \\
\hline
\end{tabular}

"Median (IQR), t: n\%), C/S: Sezaryen Doğum; CRIB skoru: Clinical Risk Index for Babies Scoring System; EMR: Erken Membran Rüptürü;

GHT: Gestasyonel Hipertansiyon; GDM: Gestasyonel Diyabetes Mellitus; SGA: Gebelik haftasına göre küçük doğum ağırlklı

Tablo II: Tam enteral beslenmeye geç bașlama için bağımsız risk faktörleri.

\begin{tabular}{l|ccc}
\hline & OR & \%95 $\mathbf{~ C l}$ & $\mathbf{p}$ \\
\hline Doğum ağırlı̆̆ı & 0.9 & $0.995-0.998$ & $<0.01$ \\
Preeklampsi & 2.5 & $1.025-6.444$ & 0.04 \\
\hline RDS & 1.9 & $1.154-3.237$ & 0.012 \\
\hline
\end{tabular}

RDS: Respiratuar Distres Sendromu

Tam enteral beslenmeye geç dönemde geçen bebeklerin gestasyon haftası ve doğum ağıllı̆̆ı anlamlı olarak düşük iken, sezaryenle doğum oranı ve annede preeklampsi varlığı daha yüksekti. Verilere lojistik regresyon analizi yapıldığında, doğum ağırlığının düşük olması, annede preeklampsi ve RDS varlığı, tam enteral beslenmede gecikme için bağımsız risk faktörleri olarak bulundu (Tablo II).

Doğum ağırlı̆̆ındaki artış bu riski azaltırken, annede preeklampsi varlığı ve bebekte RDS varlı̆ı̆ bu riski artırdı.

Preterm morbiditeler Tablo III'de özetlendi. Enteral beslenmeye geç ulaşanlarda RDS, BPD, GNS oranları anlamlı olarak daha yüksek iken $(p<0.01)$, NEK, Evre 3-4 IVK ve mortalite oranları ise gruplar arasında benzerdi.

Tam enteral beslenmeye erken dönemde geçen bebeklerde; hastanede yatış süresi daha kısaydı ( $p<0.01)$. Günlük kilo alımı açısından iki grup arasında istatistiksel fark saptanmadı.

\section{TARTIŞMA}

Bu çalışmada doğum ağırlığının düşük olmasının, RDS varlığının ve annede preeklampsi öyküsünün çok düşük doğum ağırlıklı bebeklerde tam enteral beslenmeye geçiş süresini geciktirdiği gösterildi.
Literatürde tam enteral beslenmeye ulașma süresini etkileyen faktörleri araştıran sınırlı sayıda çalışma vardır. İtalya'da çok düşük doğum ağırlıkı 1864 bebeğin dahil edildiği bir çalıșmada tam enteral beslenme, beslenme miktarının en azından $150 \mathrm{ml} /$ kg'a ulaşmış olması olarak tanımlanmıştır. Bu bebeklerin \%95.2 si tam enteral beslenmeye ulaşabilmiş, geri kalanı ise çeşitli nedenlerle hayatını kaybetmiştir. Bizim çalışmamızdan farklı olarak bebeklerin enteral beslenmeye geçiş süresi erken ya da geç olarak sınıflandirılmamış, tam enteral beslenmeye geçiş süresinin ortancası (IQR), 13(7-24) gün olarak saptanmıştır. Gebelik haftasına göre küçük doğum ağıllıkı bebek olma (SGA) ve Patent Duktus Arteriozus (PDA) tanısı almış olma bașta olmak üzere, formüla ile beslenme, sezaryen doğum şekli, yüksek CRIB skoru ve maternal hipertansiyon varlığı gecikmiş tam enteral beslenme zamanını etkileyen belirleyiciler olarak bulunmuștur (10). Çalıșmamızda 10 günden önce tam enteral beslenmeye bașlanmıș olmayı erken olarak kabul ederek karșılaștırma yapıldı ve tam enteral beslenmede gecikme olan grupta doğum ağırlığı daha düşük iken, sezaryen ile doğum öyküsü, CRIB skoru, preeklampsi oranları bu çalsşmada olduğu gibi daha yüksek bulundu. Hastaların doğum şekli veya beslenme tipinde ise fark saptanmadı.

Tam enteral beslenmeye geç ulaşan bebeklerde daha fazla RDS görülmesi, beslenme intoleransının ve RDS'nin immatürite ile ilişkisi nedeni ile şaşıtıcı değildir. Ayrıca RDS tanıı bebeklerde kullanılan solunum desteklerinin de gastrointestinal sistemde gaz distansiyonuna yol açarak beslenme intoleransının artmasına neden olabileceği bildirilmiștir (11).

Preeklampsi, gebelik boyunca ortaya çıkabilen, yaygın olarak görülen ve etyolojisi tam olarak bilinmeyen, plesental yetmezliğe ve endotel disfonksiyonuna neden olan bir komplikasyondur (12). Özellikle erken başlangıçlı preeklampsi varlı̆ında fetüs kronik iskemiye maruz kalmakta, bu da uteroplasental kan akımının 
Tablo III: Çalışmaya alınan infantların morbidite ve taburculuk sırasındaki özellikleri.

\begin{tabular}{|l|c|c|c|}
\hline & Erken $(\mathbf{n}=\mathbf{9 1})$ & Geç (n=383) & p \\
\hline RDS, $^{+}$ & $32(35.2)$ & $222(58.0)$ & $<0.01$ \\
\hline BPD, ${ }^{+}$ & $3(3.3)$ & $45(11.7)$ & 0.016 \\
\hline NEK, ${ }^{+}$ & $1(1.1)$ & $6(1.6)$ & 0.74 \\
\hline${\text { IVK (Grade 3-4) }{ }^{+}}^{+}$ & $6(6.6)$ & $49(12.8)$ & 0.09 \\
\hline GNS, $^{+}$ & $11(12.1)$ & $132(34.5)$ & $<0.01$ \\
\hline Mortalite, $^{+}$ & - & $10(2.6)$ & 0.12 \\
\hline Hastanedeki yatış süresi $^{*}$ & $43(32-57)$ & $66(51-83)$ & $<0.01$ \\
\hline Taburculuktaki VA* $^{*}$ & $1985(1785-2300)$ & $2105(1880-2545)$ & $<0.01$ \\
\hline Taburculuktaki BÇ* $^{*}$ & $31.5(30.8-32.5)$ & $32(31-33.6)$ & $<0.01$ \\
\hline Günlük kilo alımı $^{*}$ & $18(14.5-21.9)$ & $17(13.9-21)$ & 0.21 \\
\hline
\end{tabular}

*Median (IQR), t:n (\%), RDS: Respiratuar Distres Sendromu; BPD: Bronkopulmoner Displazi; NEK: Nekrotizan Enterokolit; IVK: Intraventriküler Kanama; GNS: Geç Neonatal Sepsis; VA: Vücut Ă̆ırlı̆ı;; BÇ: Baş Çevresi.

azalmasına, arteriollerde ilerleyici obliterasyona ve sklerozise neden olmaktadır (13). Preeklampsinin yenidoğanlarda beslenme intoleransına bu nedenlerden dolayı yol açtı̆̆ çeşitli çalışmalarda ortaya konulmuştur. Pezzati ve ark yaptı̆̆ı bir çallşmada, preeklamptik anne bebeklerinin prenatal ultrason incelemesinde end-diyastolik akım azalması veya kaybolmasının intestinal hipoperfüzyona neden olduğu ve beslenme problemlerinin bu bebeklerde daha fazla görüldüğü bildirilmiștir. Preeklampsinin NEK sıklı̆ını artırdığı ortaya konulmuștur (14). Ersch ve ark.'nın (15) yaptı̆̆ başka bir çalışmada da preeklamptik anne bebeklerinin beslenme problemlerinin daha sık olduğu ve bu bebeklerin hastanede yatış sürelerinin daha uzun olduğu sonucuna varımıştır. Bizim çalışmamızda da annede preeklempsi varlığının tam enteral beslenmeye geçişi geciktirmiş olması bu çalıșmaları desteklemektedir.

Tam enteral beslenmeye erken geçilmesi, santral yollara ve parenteral beslenmeye olan intiyacı ve enfeksiyon riskini azaltmaktadır (16). Yapılan çalıșmalar göstermiștir ki, erken tam enteral beslenmeye geçiş, kateter kullanımını azaltarak geç neonatal sepsis riskini azaltmaktadır. Bununla birlikte GNS de tek başına tam enteral beslenmeye geçiş süresinin uzamasına neden olabilir (17). Çallșmamızda da literatüre benzer șekilde erken dönemdeki grupta GNS oranları düşük saptanmıştır. Enteral beslenmedeki günlük 30-40 ml'lik artışlar bile çok düşük doğum ağırlıkı bebeklerde NEK riskini artırmamaktadır $(6,7,18)$. Çalışmamızda NEK açısından iki grup arasında fark saptanmamıştır.

Erken tam enteral beslenmenin yenidoğan morbiditesi ve uzun dönem etkileri açısından daha çok çalıșmaya intiyaç duyulmaktadır. Çalıșmamızda erken dönemde tam enteral beslenmeye geçen bebeklerde hastanede kalış süresi anlamlı olarak daha kısaydı. Almanya'da 2017 ylında yayınlanmış bir çalışmaya 77 aşırı preterm bebek dahil edilmiş, ortalama 7 günde tam enteral beslenmeye ulaşılmış, daha erken ulaşan bebeklerin kilo alımı ve baş çevresi büyümesi daha iyi bulunmuştur (19). Bu çalışma ileri derecede pretermlerde bile tam enteral beslenmeye erken geçişi desteklemektedir. Bizim çalıșmamızda da erken enteral beslenmeye geçen bebeklerde günlük kilo alımı ortancası (IQR) 18 gr (14.5-21.9), geç grupta ise $17 \mathrm{gr}$ (13.9-21.0)'di. Tam enteral beslenmeye erken geçen bebeklerde günlük kilo artışı daha iyi olmakla beraber aralarında anlamlı fark bulunamadı. Tam enteral beslenmeye daha geç dönemde ulaşan gruptaki bebeklerin taburculuktaki vücut ağırlıkları ve baș çevresi büyümesinin daha iyi olması da hastaların yatış sürelerinin daha uzun olmasına bağlı olabileceği düşünüldü.

Waard ve ark.'nın (20) 5 kıtada yürüttüğü, 2947 bebeğin dahil olduğu bir çalıșmada formül mama ile beslenmek ve enteral beslenmeye geç bașlamak daha fazla antibiyotik ve daha yavaş kilo alımı ile ilişkili bulunmuştur. Enteral beslenmeye erken geçilmesinin, çalışmamıza benzer şekilde NEK ve yüksek mortalite ile ilişkisi saptanmamıştır.

Sonuç olarak; yenidoğan yoğun bakım ünitelerinde izlenen preterm bebeklerin tam enteral beslenmeye erken başlaması morbiditeler üzerine fayda sağlamaktadır. Bu durum bebeklerde hastane yatış sürelerini azaltarak büyümelerine katkı sağlayabilir. Hastaların prematüritenin getirdiği düşük doğum ağırlığı ve RDS riskinden korunması, preeklamptik anne takiplerinin iyi yapılması beslenme üzerindeki olumsuz etkiyi azaltabilir.

\section{KAYNAKLAR}

1. Salas AA, Li P, Parks K, Lal CV, Martin CR, Carlo WA. Early progressive feeding in extremely preterm infants: a randomized trial. Am J Clin Nutr 2018;107:365-70.

2. Türk Neonataloji Derneği Prematüre ve Hasta Term Bebeğin Beslenmesi Rehberi 2014, http://www.neonatology.org.tr/wpcontent/uploads/2016/12/premature_rehber_son_son.pdf

3. Ong KK, Kennedy K, Castaneda-Gutierrez E, Forsyth S, Godfrey $\mathrm{KM}$, Koletzko B, et al. Postnatal growth in preterm infants and later health outcomes: a systematic review. Acta Paediatr 2015;104:974-86.

4. Tipici BE, Akbulut G. Preterm yenidoğanlarda enteral beslenme desteği. Beslenme ve Diyet Dergisi 2014;42:59-64. 
5. Cortez J, Makker K, Kraemer DF, Neu J, Sharma R, Hudak ML. Maternal milk feedings reduce sepsis, necrotizing enterocolitis and improve outcomes of premature infants. J Perinatol 2018;38:71-4.

6. Corpeleijn WE, Kouwenhoven SM, Paap MC, Vliet IV, Scheerder I, Muizer $Y$, et al. Intake of own mother's milk during the first days of life is associated with decreased morbidity and mortality in very low birth weight infants during the first 60 days of life. Neonatology 2012;102:276-81.

7. Barr PA, Mally PV, Caprio MC. Standardized Nutrition Protocol for Very Low-Birth-Weight Infants Resulted in Less Use of Parenteral Nutrition and Associated Complications, Better Growth, and Lower Rates of Necrotizing Enterocolitis. JPEN J Parenter Enteral Nutr 2018;43:540-9.

8. Manea A, Boia M, lacob D, Dima M, lacob RE. Benefits of early enteral nutrition in extremely low birth weight infants. Singapore Med J 2016;57:616-8.

9. Thureen PJ. The Neonatologist's Dilemma: Catch-up Growth or Beneficial Undernutrition in Very Low Birth Weight Infants-What Are Optimal Growth Rates? J Pediatr Gastroenterol Nutr 2017;45:1524.

10. Corvaglia L, Fantini MP, Aceti A, Gibertoni D, Rucci P, Baronciani D, et al. Predictors of full enteral feding achievement in very low birth weight infants. PLoS One 2014;9:e92235.

11. Cresi F, Maggiora E, Borgione SM, Spada E, Coscia A, Bertino E, et al. Enteral Nutrition Tolerance And REspiratory Support (ENTARES) Study in preterm infants: study protocol for a randomized controlled trial. Trials 2019;20:67.

12. Kongwattananakul $K$, Saksiriwuttho $P$, Chaiyarach $S$, Thepsuthammarat K. Incidance, characteristics, maternal complications and perinatal outcomes associated with preeclampsia with severe features and HELLP syndrome. Int J Womans Health 2018;10:371-7.
13. Zuspan FP, New concepts in the understanding of hypertansive diseases during pregnancy. Clin Perinatol 1991;18:653-9.

14. Pezzati M, Dani C, Tronchin M, Filippi L, Rossi S, Rubaltelli FF. Prediction of early tolerance to enteral feeding by measurement of superior mesenteric artery blood flow velocity: appropriateversus small-for-gestational-age preterm infants. Acta Pediatrica 2004; 93:797-802.

15. Ersch J, Baenziger O, Bernet V, Bucher HU. Feeding problems in preterm infants of preeklamptic mothers. J Paediatr Child Health 2008;44:651-5.

16. Kandasamy Y. Infection control during administration of parenteral nutrition in preterm babies. Arch Dis Child Fetal Neonatal Ed. 2009;94:78.

17. Boghossian NS, Page GP, Bell EF, Stoll BJ, Murray JC, Cotten $\mathrm{CM}$, et al. Late-onset sepsis in very low birth weight infants from singleton and multiple-gestation births. J Pediatr 2013;162:11201124.e1.

18. Nangia S, Vadivel V, Thukral A, Saili A. Early Total Enteral Feeding versus Conventional Enteral Feeding in Stable Very-Low-BirthWeight Infants: A Randomised Controlled Trial. Neonatology 2019;115:256-62.

19. Maas C, Franz AR, Krogh Svon, Arand J, Poets CF. Growth and morbidity of extremely preterm infants after early full enteral nutrition. Arch Dis Child Fetal Neonatal Ed 2017;0:1-3

20. Waard M, Li Y, Zhu Y, Ayede A, Berrington J, Bloomfield FH, et al. Time to Full Enteral Feeding for Very Low-Birth-Weight Infants Varies Markedly Among Hospitals Worldwide But May Not Be Associated With Incidence of Necrotizing Enterocolitis: The NEOMUNE-NeoNutriNet Cohort Study. JPEN J Parenter Enteral Nutr 2019: 43:658-67. 